\title{
Eribulin sensitizes oral squamous cell carcinoma cells to cetuximab via induction of mesenchymal-to-epithelial transition
}

\author{
HIROKO KITAHARA $^{1}$, MARIKO HIRAI ${ }^{1}$, KOROKU KATO ${ }^{1}$, GEORGE BOU-GHARIOS ${ }^{2}$, \\ HIROYUKI NAKAMURA ${ }^{1}$ and SHUICHI KAWASHIRI ${ }^{1}$ \\ ${ }^{1}$ Department of Oral and Maxillofacial Surgery, Division of Cancer Medicine, \\ Kanazawa University Graduate School of Medical Science, Kanazawa, Ishikawa 920-8640, Japan; \\ ${ }^{2}$ Institute of Ageing and Chronic Disease, University of Liverpool, Liverpool L7 8TX, UK
}

Received June 14, 2016; Accepted October 17, 2016

DOI: 10.3892/or.2016.5189

\begin{abstract}
Inhibition of epidermal growth factor receptor (EGFR) signalling has emerged as a new treatment strategy for oral squamous cell carcinoma (OSCC). Previously, we found that loss of EGFR expression in OSCC was associated with epithelial-mesenchymal transition (EMT), and may have functional implications with regard to resistance to cetuximab, a monoclonal anti-EGFR antibody. Eribulin (a microtubule inhibitor) reportedly renders breast cancer less aggressive, and less likely to metastasise, by triggering mesenchymal-to-epithelial (MET) transition. In the present study we evaluated whether eribulin-induced MET was associated with re-sensitization of resistant OSCC cell lines to cetuximab. In vitro antiproliferative activities were determined in three human OSCC lines (OSC-20, OSC-19 and HOC313) treated with eribulin. These three human OSCC represented different EMT/MET states. Interestingly, HOC313 cells (mesenchymal phenotype) were highly sensitive to eribulin in comparison with other cell lines, and significantly enhanced the antiproliferative effect of cetuximab in response to the drug. Eribulin also underwent a MET-associated gene switch that resulted in morphological changes and high EGFR expression in HOC 313 cells, and abrogated a TGF- $\beta$-induced EMT gene expression signature. Eribulin-dependent sensitization of OSCC to cetuximab is likely due to induction of MET. Combination therapies based on eribulin and cetuximab have potential as a novel treatment regimen in OSCC.
\end{abstract}

Correspondence to: Dr Hiroyuki Nakamura, Department of Oral and Maxillofacial Surgery, Division of Cancer Medicine, Kanazawa University Graduate School of Medical Science, 13-1 Takara-machi, Kanazawa, Ishikawa 920-8640, Japan

E-mail: hnak@me.com

Key words: eribulin, oral cancer, epidermal growth factor receptor, cetuximab, epithelial-mesenchymal transition

\section{Introduction}

Epidermal growth factor receptor (EGFR/ErbB1/HER1) is overexpressed in a majority of oral squamous cell carcinomas (OSCC), and high expression levels are associated with a more aggressive phenotype, poor prognosis and resistance to cancer therapy (1). In recent years, inhibition of EGFR signalling has emerged as a new treatment strategy for OSCC. A number of anti-EGFR antibodies (including cetuximab and panitumumab) and small-molecule tyrosine kinase inhibitors (including gefitinib and erlotinib) that target EGFR have been developed (2). However, only the monoclonal antibody cetuximab has been approved for the treatment of advanced OSCC (3). Cetuximab is effective in recurrent or metastatic OSCC both as a first-line treatment in combination with platinum-based chemotherapy (4-7) and as a second-line treatment in patients with platinum-refractory disease (8-10). The sensitivity of some tumours to cetuximab can be explained by the presence of mutations in the EGFR tyrosine kinase domain $(11,12)$. However, such mutations are rare in OSCC (13). We have found that EGFR status may influence the response to cetuximab treatment (14). However, there are currently no effective treatment strategies for cetuximab-resistant OSCC in which EGFR expression has been downregulated.

Involvement of epithelial-mesenchymal transition (EMT) in drug resistance occurs in several cancer types. For instance, the mesenchymal marker vimentin is upregulated in specimens from non-small cell lung cancer (NSCLC) patients who develop resistance to EGFR inhibitors, suggesting that EMT has been triggered in such tumours (15-17). In our previous study, we found that loss of EGFR expression in OSCC was associated with EMT, and may have functional implications in the resistance to cetuximab treatments (14). Yoshida et al demonstrated that eribulin may also render residual tumours less aggressive and less likely to metastasise by reversing EMT, and inducing a mesenchymal-to-epithelial transition (MET) (18). Eribulin is a non-taxane inhibitor of microtubule dynamics that exerts its primary pharmacologic effects by preventing normal mitotic spindle formation, leading to irreversible mitotic blockage and subsequent cell death by apoptosis (19-22). Eribulin 
binds to the plus ends of microtubules (23), thereby disrupting microtubule dynamics by a mechanism distinct from those of other clinically used tubulin agents including epothilones, vinca alkaloids and taxanes. Eribulin is currently approved for clinical use for treatment of certain patients with advanced breast cancer. For instance, in the United States, EU and Japan, eribulin is approved for patients with locally invasive or metastatic breast cancer who have previously received at least two chemotherapeutic regimens for metastatic disease, including an anthracycline and a taxane (24). However, the efficacy of eribulin in OSCC has not yet been examined.

In the present study, we evaluated whether there were any correlations between eribulin-dependent MET and sensitivity of human OSCC cell lines to cetuximab treatment. Our findings indicate that eribulin should be considered as part of a combination therapy to re-sensitize OSCC to cetuximab.

\section{Materials and methods}

Cell culture. Three human oral squamous cell carcinoma cell lines established from tumour biopsies with different invasive potential and EMT/MET status were obtained. These were OSC-20 (low-grade invasive cells, epithelial phenotype), OSC-19 (low-grade invasive cells, epithelial phenotype), and HOC313 (high-grade invasive cells, mesenchymal phenotype). OSC-20 is a cell line derived from a 58-year-old female with tongue cancer that metastasized to the cervical lymph nodes (25). OSC-19 was derived from a 61-year-old male with tongue cancer that metastasized to the cervical lymph nodes (26). HOC313 was derived from a 51-year-old woman with squamous cell carcinoma (involving the mandibular gingiva and oral floor) that metastasized to the cervical lymph nodes (27). In addition, normal human dermal fibroblast cells (NHDF) were used as a control. NHDF were obtained from the American Type Culture Collection (Manassas, VA, USA). These cells were cultured in DMEM medium (Sigma-Aldrich, Tokyo, Japan) supplemented with 10\% FBS (HyClone, Logan, UT, USA). Recombinant EGF and transforming growth factor- $\beta 1$ (TGF- $\beta 1$ ) was purchased from R\&D Systems (Minneapolis, MN, USA). Eribulin (Halaven) was purchased from Eisai Co., Ltd. (Tsukuba, Japan). Cetuximab (Erbitux) was purchased from Merck Serono (Tokyo, Japan). Cetuximab was diluted in DMEM medium supplemented with 10\% FBS and $100 \mathrm{ng} / \mathrm{ml}$ EGF.

Proliferation assay. Cells were plated in 96-well plates and cultured with the indicated concentration of compounds for 3 days, followed by cell number and viability determinations as measured by CellTiter 96 AQueous One Solution Cell Proliferation assay (Promega, Madison, WI, USA) according to the manufacturer's protocols. The optical density at $490 \mathrm{~nm}$ was measured using a microplate reader (iMark microplate reader; Bio-Rad, Hercules, CA, USA). Mean $\mathrm{IC}_{50}$ values were calculated based on $\mathrm{IC}_{50}$ values generated from separate sigmoidal curves representing the growth inhibition activity versus eribulin concentrations in 3 independent experiments. The data are presented as the mean values \pm SEM.

RNA extraction, cDNA synthesis and quantitative real-time PCR ( $q$ PCR). The levels of EGFR, E-cadherin, $N$-cadherin, vimentin and Snaill mRNAs were analysed using a Rotor-Gene Q 2plex System (Qiagen, Hilden, Germany) with FAM/ZEN/IBFQ probes (DNA sequence was not released; Integrated DNA Technologies, Inc., Coralville, IA, USA). Total RNA was extracted with the RNeasy Protect Mini kit (Qiagen, Hilden, Germany) and cDNA was obtained using PrimeScript First Strand cDNA synthesis kit (Takara, Tokyo, Japan). All reactions and conditions followed the manufacturer's instructions. We amplified 18S rRNA as an internal standard using HEX/ZEN/IBFQ probes (DNA sequence was not released; Integrated DNA Technologies, Inc.). Data were calculated using the $\Delta \Delta \mathrm{Ct}$ method for qPCR (28), which presents the data as a fold difference in expression level relative to a control sample; in this case, the mean expression of the vehicle-treated cells.

EMT induction. OSC-20 cells were seeded at $70 \%$ confluence and cultured for 48 or $72 \mathrm{~h}$ in Dulbecco's modified Eagle's medium (Sigma-Aldrich) with $0.5 \%$ foetal bovine serum (HyClone) to induce EMT. Recombinant human TGF- $\beta 1$ (R\&D Systems) was added to a final concentration of $5 \mathrm{ng} / \mathrm{ml}$.

Immunocytochemistry. Cells, cultured on cover glass (Matsunami, Tokyo, Japan) were fixed with $4 \%$ paraformaldehyde. To detect localization of EGFR in cells, mouse anti-EGFR antibody (Dako, Tokyo, Japan) was used for staining. The cells were further incubated with Alexa Fluor 488-labeled goat anti-mouse IgG (Cell Signaling Technology, Tokyo, Japan). After mounting with ProLong Gold Antifade Reagents (Thermo Fisher Scientific, Tokyo, Japan) the cells were subjected to fluorescence microscopy.

Western blot analysis. The cultured cells were lysed with Pierce RIPA buffer (Thermo Fisher Scientific, Waltham, MA, USA). Lysates mixed with sample buffer were electrophoretically separated and transferred onto membranes. The membranes were blocked with Blocking One (Nacalai Tesque, Kyoto, Japan), followed by incubations with anti-EGFR antibody (Dako) and anti-human $\beta$-actin antibody (Cell Signaling Technology). After washing with TBS-0.05\% Tween-20, membranes were incubated with HRP-conjugated anti-mouse IgG. After washing with TBS-0.05\% Tween-20, membranes were incubated with ECL Prime Western Blotting Detection reagent (GE Healthcare, Little Chalfont, UK). Signals were detected and analysed using C-DiGit (M\&S TechnoSystems, Tokyo, Japan).

Statistical analysis. Statistical analyses were conducted using JMP 12.0 (SAS Institute, Inc., Cary, NC, USA). The differences between groups were tested for statistical significance using the two-tailed Mann-Whitney $U$ test. Differences were considered significant at $\mathrm{P}<0.05$.

\section{Results}

Eribulin sensitivity in OSCC cell lines. In vitro antiproliferative activities $\left(\mathrm{IC}_{50}\right)$ were determined in all three OSCC lines treated with eribulin (Fig. 1). One day after plating, serial dilutions of eribulin were added to cells for 3 days. Mean $\mathrm{IC}_{50}$ values for OSC-20, OSC-19 and HOC313 are 3.33, 4.15 and $0.03 \mathrm{nM}$, 

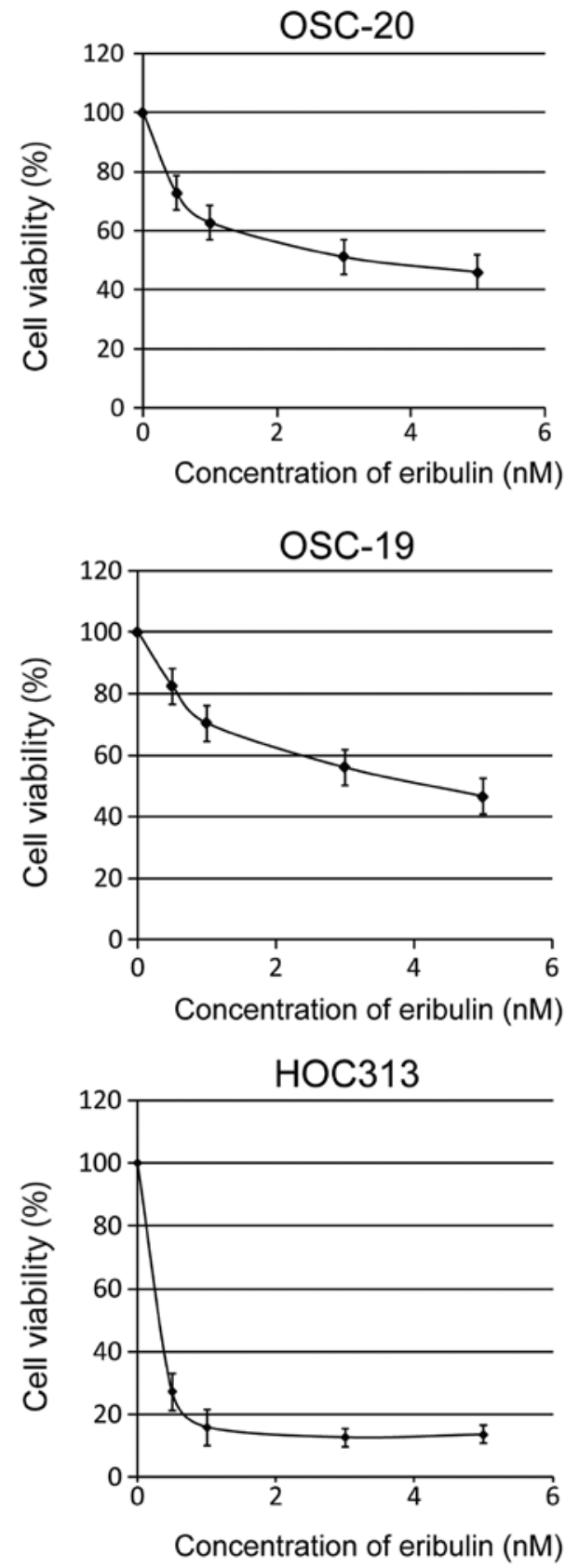

Figure 1. Eribulin sensitivity of oral squamous cell carcinoma (OSCC) cell lines with different invasive capabilities. In vitro antiproliferative activities $\left(\mathrm{IC}_{50}\right)$ were determined in all three OSCC lines treated with eribulin. $\mathrm{IC}_{50}$ values for OSC-20, OSC-19 and HOC313 were 3.33, 4.14 and $0.07 \mathrm{nM}$ respectively. The data are presented as the mean values \pm SEM from triplicate experiments.

respectively; thus, HOC313 cells are $~ 100$ times more sensitive to eribulin when compared to the other two lines.

Cetuximab sensitivity of eribulin-treated OSCC cell lines. To evaluate the effect of eribulin on cetuximab-resistant OSCC cells, we used HOC313 cells. Eribulin-treated HOC313 cells were incubated for 24 or $48 \mathrm{~h}$ with various concentrations of cetuximab $(0,0.005$ and $0.01 \mu \mathrm{g} / \mathrm{ml})$. The proliferation of eribulin-treated HOC313 cells was significantly inhibited compared to control cells (Fig. 2A). In the absence of eribulin, however, cetuximab has no anti-proliferative effects in HOC313 cells (Fig. 2B). Conversely, in the absence of
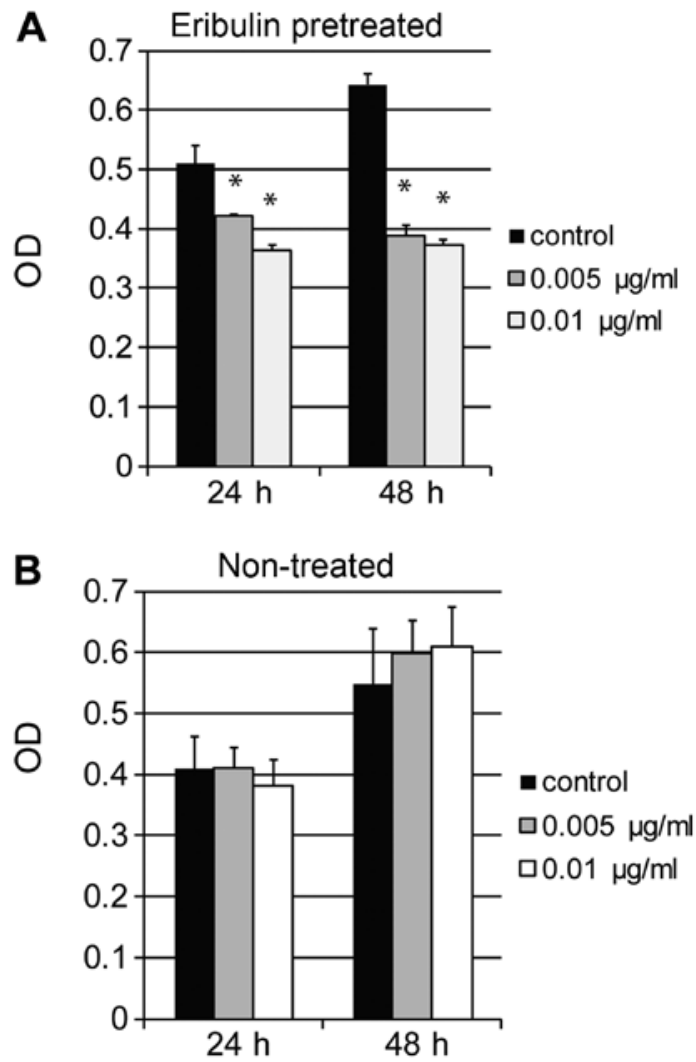

Figure 2. Cetuximab inhibited proliferation of eribulin-pretreated cell lines. (A) Eribulin pretreated or (B) non-treated HOC313 cells were incubated with various concentrations of cetuximab as indicated and the anti-proliferative effect of cetuximab was determined using an MTT assay. Each data point represents the mean of three independent experiments. The vertical bars show standard deviations. Error bars correspond to SEM. ${ }^{*} \mathrm{P}<0.05$.

cetuximab, eribulin increased the proliferative index of HOC313 cells $\sim 1.25$-fold.

Eribulin sensitizes HOC313 cells to cetuximab by upregulating EGFR and inducing MET. Previously, we demonstrated that the HOC313 displayed a mesenchymal phenotype that was accompanied by loss of $E$-cadherin and acquisition of $N$-cadherin, vimentin and Snail expression (14). Thus, HOC313 cells were chosen as a model to study the effects of eribulin on MET. Following eribulin treatment, RNA from surviving HOC313 cells was subjected to qPCR analysis. Eribulin treatment consistently upregulated expression of EGFR and E-cadherin, while it downregulated the mesenchymal markers $N$-cadherin, vimentin and Snail (Fig. 3A). Eribulin treated HOC313 cells were no longer spindle shaped like the control, but instead had flat, more epithelial-like morphologies (Fig. 3B). This conversion from mesenchymal to epithelial-like morphology confirmed the observed alterations in EMT/MET-related genes (Fig. 3A). Upregulation of EGFR was confirmed at the protein level by immunocytochemistry (Fig. 3B) and immunoblotting (Fig. 3C).

Eribulin downregulates genes induced by TGF- $\beta$ signalling. The above results suggest that eribulin can transcriptionally reprogram cells in order to achieve MET. To study this in more detail, we asked whether eribulin could prevent the reverse process (i.e., EMT) that is induced by the cytokine TGF- $\beta$. For 


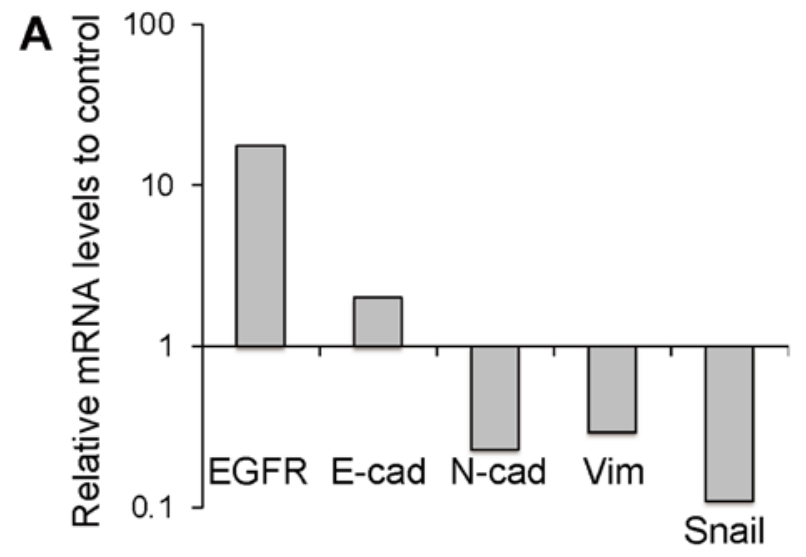

B
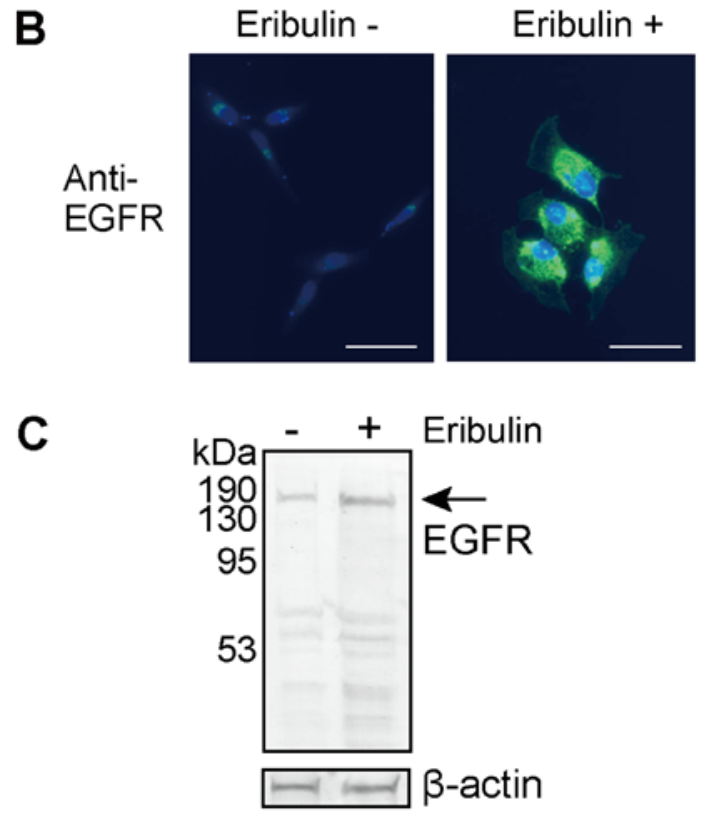

Figure 3. Eribulin treatment of HOC313 cells in vitro induces mesenchymalepithelial transition (MET). HOC313 cells were treated with eribulin or control vehicle for 5 days, at the $\mathrm{IC}_{50}$ doses of eribulin. (A) Relative expression levels of epidermal growth factor receptor $(E G F R)$ and the epithelial-mesenchymal transition (EMT)-associated genes E-cadherin, $N$-cadherin, vimentin and Snail mRNAs in eribulin-treated HOC313 cell lines. Expression levels are displayed as fold differences relative to the vehicle-treated controls. (B) Representative images of HOC313 cells following treatment with eribulin. Alexa Fluor 488-labelled anti-mouse IgG was used to detect EGFR antibody (green). Scale bar, $50 \mu \mathrm{m}$. (C) Expression of EGFR protein as assessed by immunoblot analysis. Arrow indicates EGFR, and $\beta$-actin was used as a loading control.

this, we used OSC-20 cells, as they have an epithelial phenotype, and undergo EMT in response to TGF- $\beta$ (14). Following treatment with TGF- $\beta$ and/or eribulin, the expression profiles of epithelial and mesenchymal markers were analysed (Fig. 4). Eribulin inhibited TGF- $\beta$-dependent downregulation of $E$-cadherin and also prevented upregulation of the mesenchymal markers $N$-cadherin, vimentin and Snail. Interestingly, eribulin treatment alone had no effect on MET.

\section{Discussion}

We found that cetuximab-resistant cells with a mesenchymal phenotype are particularly sensitive to eribulin. EMT is a

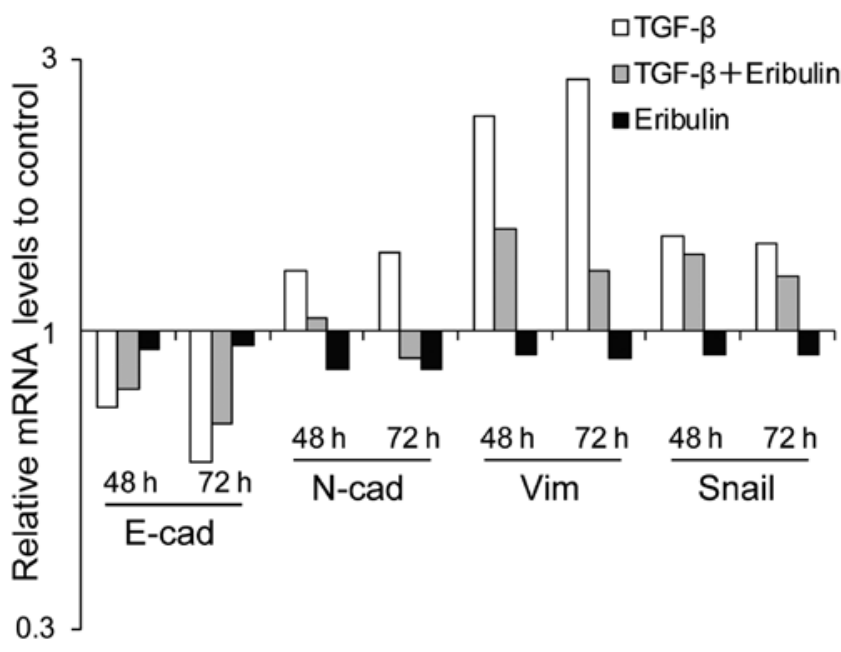

Figure 4. Eribulin antagonizes transforming growth factor- $\beta 1$ (TGF- $\beta$ ) signalling. OSC-20 cells were treated with TGF- $\beta$ and eribulin (at the $\mathrm{IC}_{50}$ dose of $3.33 \mathrm{nM}$ ) or the single agents for 48 or $72 \mathrm{~h}$. Relative expression levels of epithelial-mesenchymal transition (EMT)-associated genes E-cadherin, $N$-cadherin, vimentin and Snail mRNAs are shown. The expression levels are displayed as fold differences relative to vehicle-treated controls.

process in which epithelial cells acquire mesenchymal properties and show loss of intercellular cohesion, increased cellular migration, and increased resistance to anticancer agents. Importantly, the EMT signature correlates with eribulin resistance in breast cancer cells in vitro (29), cisplatin resistance in ovarian cancer $(30,31)$, and resistance to gemcitabine, 5-FU and cisplatin in pancreatic cancer (32). Our previous study demonstrated that the EMT-associated genes $N$-cadherin, vimentin and Snail were upregulated in HOC313 cells (14). We report that an EMT gene expression profile is a predictor of eribulin sensitivity in OSCC, which contrasts with previous findings in other tumour types. While the molecular mechanisms that account for this difference remain to be determined, we suggest that they may be confined to cancer subtypes with a unique molecular profile. Clearly, further investigation will be required to test this hypothesis.

Involvement of EMT in resistance to EGFR inhibitors has been reported in several cancer types. For instance, specimens from NSCLC patients who develop resistance to EGFR inhibitors are vimentin-positive, suggesting that EMT has been triggered in such tumours (15-17). In our previous study, the EMT-associated genes, $N$-cadherin, vimentin and Snail were upregulated in cetuximab-resistant OSCC cells (14). We also demonstrated that TGF- $\beta$ induced EMT in an OSCC cell line (OSC-20) that correlated with loss of EGFR expression, and a phenotypic switch from cetuximab-sensitive to cetuximabresistant (14). This is consistent with reports that the response to EGFR-targeted agents is inversely correlated with EMT in tumours without known EGFR mutations, including OSCC, NSCLC, bladder, colorectal, pancreas and breast carcinomas (33-37). Yoshida et al demonstrated that eribulin promoted a shift from EMT to MET in breast carcinoma cells in vitro (18). Thus, we investigated potential relationships between eribulin-dependent switches in the EMT/MET balance and sensitivity to EGFR inhibitors in OSCC. We found that eribulin sensitizes HOC313 cells to cetuximab by inducing MET, thus revealing a novel biological activity 
associated with eribulin. Eribulin-induced MET is associated with upregulation of EGFR, providing a plausible explanation for the sensitization to cetuximab. However, further studies are necessary to elucidate the precise molecular mechanisms governing this cetuximab sensitivity.

Eribulin treatment prevents TGF- $\beta$-dependent induction of an EMT signature, suggesting that eribulin-dependent MET was, at least in part, due to inhibition of TGF- $\beta$ signalling (Fig. 4). Several studies indicate that the primary targets of eribulin are tubulin and microtubules $(19-21,23,38)$. Smad proteins, which are essential mediators of the TGF- $\beta$ signalling pathway, normally bind microtubules in the absence of TGF- $\beta$ but dissociate from them upon TGF- $\beta$ stimulation (39). Dissociated Smad 2 and Smad3 become phosphorylated and then associate with Smad4, followed by translocation of the entire complex to the nucleus where it activates transcription. Eribulin inhibits the growth phase of microtubule dynamics (38) by binding to high-affinity sites on microtubule plus ends (23). This may stabilize the association between Smad proteins and microtubules, and consequently inhibit Smad phosphorylation and activation. However, we cannot exclude the possibility that eribulin may target other molecules in order to promote MET. It would be interesting to determine whether other tubulin-targeting agents, such as the taxanes, vinca alkaloids, or epothilones, have similar effects on the EMT/MET balance.

In conclusion, we have shown that eribulin can increase the sensitivity to cetuximab by inducing MET in cetuximab-resistant OSCC, and that this is correlated with suppression of TGF- $\beta$ signalling in epithelial type OSCC. Therefore, combination therapies with eribulin and cetuximab should be considered as a new treatment regimen for both epithelial and mesenchymal type OSCC. We hope that the results of the present study will provide an impetus for future investigations of novel treatment strategies for OSCC.

\section{Acknowledgements}

This study was supported by a grant-in-aid for Scientific Research from the Ministry of Education, Science, Sports and Culture, Japan (nos. 15K20510 and 20390504 to H.K.; no. 26463038 to K.K.; no. 25462882 to H.N.; no. $15 \mathrm{H} 05042$ to S.K.). The funders had no role in the study design, data collection, and analysis, decision to publish, or preparation of the manuscript. We are grateful to the members of the Department of Oral and Maxillofacial Surgery of Kanazawa University for their helpful suggestions and assistance. We thank Elsevier Premium Language Editing Services for assistance with language editing.

\section{References}

1. Ang KK, Berkey BA, Tu X, Zhang HZ, Katz R, Hammond EH, Fu KK and Milas L: Impact of epidermal growth factor receptor expression on survival and pattern of relapse in patients with advanced head and neck carcinoma. Cancer Res 62: 7350-7356, 2002.

2. Mahipal A, Kothari N and Gupta S: Epidermal growth factor receptor inhibitors: Coming of age. Cancer Control 21: 74-79, 2014

3. Loeffler-Ragg J, Schwentner I, Sprinzl GM and Zwierzina H: EGFR inhibition as a therapy for head and neck squamous cell carcinoma. Expert Opin Investig Drugs 17: 1517-1531, 2008.
4. Bourhis J, Rivera F, Mesia R, Awada A, Geoffrois L, Borel C, Humblet Y, Lopez-Pousa A, Hitt R, Vega Villegas ME, et al: Phase I/II study of cetuximab in combination with cisplatin or carboplatin and fluorouracil in patients with recurrent or metastatic squamous cell carcinoma of the head and neck. J Clin Oncol 24: 2866-2872, 2006.

5. Burtness B, Goldwasser MA,Flood W, Mattar B and Forastiere AA; Eastern Cooperative Oncology Group: Phase III randomized trial of cisplatin plus placebo compared with cisplatin plus cetuximab in metastatic/recurrent head and neck cancer: An Eastern Cooperative Oncology Group study. J Clin Oncol 23: 8646-8654, 2005.

6. Shin DM, Donato NJ, Perez-Soler R, Shin HJ, Wu JY, Zhang P, Lawhorn K, Khuri FR, Glisson BS, Myers J, et al: Epidermal growth factor receptor-targeted therapy with $\mathrm{C} 225$ and cisplatin in patients with head and neck cancer. Clin Cancer Res 7: 1204-1213, 2001.

7. Vermorken JB, Mesia R, Rivera F, Remenar E, Kawecki A, Rottey S, Erfan J, Zabolotnyy D, Kienzer HR, Cupissol D, et al: Platinum-based chemotherapy plus cetuximab in head and neck cancer. N Engl J Med 359: 1116-1127, 2008.

8. Baselga J, Trigo JM, Bourhis J, Tortochaux J, Cortés-Funes H, Hitt R, Gascón P, Amellal N, Harstrick A and Eckardt A: Phase II multicenter study of the antiepidermal growth factor receptor monoclonal antibody cetuximab in combination with platinumbased chemotherapy in patients with platinum-refractory metastatic and/or recurrent squamous cell carcinoma of the head and neck. J Clin Oncol 23: 5568-5577, 2005.

9. Herbst RS, Arquette M, Shin DM, Dicke K, Vokes EE, Azarnia N, Hong WK and Kies MS: Phase II multicenter study of the epidermal growth factor receptor antibody cetuximab and cisplatin for recurrent and refractory squamous cell carcinoma of the head and neck. J Clin Oncol 23: 5578-5587, 2005.

10. Vermorken JB, Trigo J, Hitt R, Koralewski P, Diaz-Rubio E, Rolland F, Knecht R, Amellal N, Schueler A and Baselga J: Open-label, uncontrolled, multicenter phase II study to evaluate the efficacy and toxicity of cetuximab as a single agent in patients with recurrent and/or metastatic squamous cell carcinoma of the head and neck who failed to respond to platinum-based therapy. J Clin Oncol 25: 2171-2177, 2007.

11. Lynch TJ, Bell DW, Sordella R, Gurubhagavatula S, Okimoto RA, Brannigan BW, Harris PL, Haserlat SM, Supko JG, Haluska FG, et al: Activating mutations in the epidermal growth factor receptor underlying responsiveness of non-small-cell lung cancer to gefitinib. N Engl J Med 350: 2129-2139, 2004.

12. Paez JG, Jänne PA, Lee JC, Tracy S, Greulich H, Gabriel S, Herman P, Kaye FJ, Lindeman N, Boggon TJ, et al: EGFR mutations in lung cancer: Correlation with clinical response to gefitinib therapy. Science 304: 1497-1500, 2004.

13. Lemos-González Y, Páez de la Cadena M, Rodríguez-Berrocal FJ, Rodríguez-Piñeiro AM, Pallas E and Valverde D: Absence of activating mutations in the EGFR kinase domain in Spanish head and neck cancer patients. Tumour Biol 28: 273-279, 2007.

14. Kimura I, Kitahara H, Ooi K, Kato K, Noguchi N, Yoshizawa K, Nakamura $\mathrm{H}$ and Kawashiri S: Loss of epidermal growth factor receptor expression in oral squamous cell carcinoma is associated with invasiveness and epithelial-mesenchymal transition. Oncol Lett 11: 201-207, 2016.

15. Uramoto $H$, Iwata $T$, Onitsuka $T$, Shimokawa $H$, Hanagiri $T$ and Oyama T: Epithelial-mesenchymal transition in EGFR-TKI acquired resistant lung adenocarcinoma. Anticancer Res 30: 2513-2517, 2010.

16. Chung JH, Rho JK, Xu X, Lee JS, Yoon HI, Lee CT, Choi YJ, Kim HR, Kim CH and Lee JC: Clinical and molecular evidences of epithelial to mesenchymal transition in acquired resistance to EGFR-TKIs. Lung Cancer 73: 176-182, 2011.

17. Sequist LV, Waltman BA, Dias-Santagata D, Digumarthy S, Turke AB, Fidias P, Bergethon K, Shaw AT, Gettinger S, Cosper AK, et al: Genotypic and histological evolution of lung cancers acquiring resistance to EGFR inhibitors. Sci Transl Med 3: 75ra26, 2011.

18. Yoshida T, Ozawa Y, Kimura T, Sato Y, Kuznetsov G, Xu S, Uesugi M, Agoulnik S, Taylor N, Funahashi Y, et al: Eribulin mesilate suppresses experimental metastasis of breast cancer cells by reversing phenotype from epithelial-mesenchymal transition (EMT) to mesenchymal-epithelial transition (MET) states. Br J Cancer 110: 1497-1505, 2014.

19. Towle MJ, Salvato KA, Budrow J, Wels BF, Kuznetsov G, Aalfs KK, Welsh S, Zheng W, Seletsky BM, Palme MH, et al: In vitro and in vivo anticancer activities of synthetic macrocyclic ketone analogues of halichondrin B. Cancer Res 61: 1013-1021, 2001. 
20. Kuznetsov G, Towle MJ, Cheng H, Kawamura T, TenDyke K, Liu D, Kishi Y, Yu MJ and Littlefield BA: Induction of morphological and biochemical apoptosis following prolonged mitotic blockage by halichondrin B macrocyclic ketone analog E7389. Cancer Res 64: 5760-5766, 2004.

21. Okouneva T,Azarenko O, Wilson L, Littlefield BA and Jordan MA: Inhibition of centromere dynamics by eribulin (E7389) during mitotic metaphase. Mol Cancer Ther 7: 2003-2011, 2008.

22. Towle MJ, Nomoto K, Asano M, Kishi Y, Yu MJ and Littlefield BA: Broad spectrum preclinical antitumor activity of eribulin (Halaven(R)): Optimal effectiveness under intermittent dosing conditions. Anticancer Res 32: 1611-1619, 2012.

23. Smith JA, Wilson L, Azarenko O, Zhu X, Lewis BM, Littlefield BA and Jordan MA: Eribulin binds at microtubule ends to a single site on tubulin to suppress dynamic instability. Biochemistry 49: 1331-1337, 2010.

24. Cortes J, O'Shaughnessy J, Loesch D, Blum JL, Vahdat LT, Petrakova K, Chollet P, Manikas A, Diéras V, Delozier T, et al; EMBRACE (Eisai Metastatic Breast Cancer Study Assessing Physician's Choice Versus E7389) investigators: Eribulin monotherapy versus treatment of physician's choice in patients with metastatic breast cancer (EMBR ACE): A phase 3 open-label randomised study. Lancet 377: 914-923, 2011.

25. Yokoi T, Hirata S, Nishimura F, Miyakawa A, Odajima T and Kohama G: Some properties of a newly established human cell line derived from an oral squamous carcinoma. Tumor Res 25 : 93-91-93, 1990.

26. Yokoi T, Homma $\mathrm{H}$ and Odajima T: Establishment and characterization of OSC-19 cell line in serum and protein free culture. Tumor Res 24: 1-17, 1988.

27. Ishisaki A, Oida S, Momose F, Amagasa T, Rikimaru K, Ichijo H and Sasaki S: Identification and characterization of autocrinemotility-factor-like activity in oral squamous-cell-carcinoma cells. Int J Cancer 59: 783-788, 1994.

28. Livak KJ and Schmittgen TD: Analysis of relative gene expression data using real-time quantitative PCR and the 2(-Delta Delta C(T)) method. Methods 25: 402-408, 2001.

29. Dezső Z, Oestreicher J, Weaver A, Santiago S, Agoulnik S, Chow J, Oda Y and Funahashi Y: Gene expression profiling reveals epithelial mesenchymal transition (EMT) genes can selectively differentiate eribulin sensitive breast cancer cells. PLoS One 9: e106131, 2014.
30. Boyer B, Vallés AM and Edme N: Induction and regulation of epithelial-mesenchymal transitions. Biochem Pharmacol 60: 1091-1099, 2000

31. Helleman J, Smid M, Jansen MP, van der Burg ME and Berns EM: Pathway analysis of gene lists associated with platinum-based chemotherapy resistance in ovarian cancer: The big picture. Gynecol Oncol 117: 170-176, 2010.

32. Haslehurst AM, Koti M, Dharsee M, Nuin P, Evans K, Geraci J, Childs T, Chen J, Li J, Weberpals J, et al: EMT transcription factors snail and slug directly contribute to cisplatin resistance in ovarian cancer. BMC Cancer 12: 91, 2012.

33. Yauch RL, Januario T, Eberhard DA, Cavet G, Zhu W, Fu L, Pham TQ, Soriano R, Stinson J, Seshagiri S, et al: Epithelial versus mesenchymal phenotype determines in vitro sensitivity and predicts clinical activity of erlotinib in lung cancer patients. Clin Cancer Res 11: 8686-8698, 2005.

34. Thomson S, Petti F, Sujka-Kwok I, Epstein D and Haley JD: Kinase switching in mesenchymal-like non-small cell lung cancer lines contributes to EGFR inhibitor resistance through pathway redundancy. Clin Exp Metastasis 25: 843-854, 2008.

35. Thomson S, Buck E, Petti F, Griffin G, Brown E, Ramnarine N, Iwata KK, Gibson N and Haley JD: Epithelial to mesenchymal transition is a determinant of sensitivity of non-small-cell lung carcinoma cell lines and xenografts to epidermal growth factor receptor inhibition. Cancer Res 65: 9455-9462, 2005.

36. Adam L, Zhong M, Choi W, Qi W, Nicoloso M, Arora A, Calin G, Wang H, Siefker-Radtke A, McConkey D, et al: miR-200 expression regulates epithelial-to-mesenchymal transition in bladder cancer cells and reverses resistance to epidermal growth factor receptor therapy. Clin Cancer Res 15: 5060-5072, 2009.

37. Barr S, Thomson S, Buck E, Russo S, Petti F, Sujka-Kwok I, Eyzaguirre A, Rosenfeld-Franklin M, Gibson NW, Miglarese M, et al: Bypassing cellular EGF receptor dependence through epithelial-to-mesenchymal-like transitions. Clin Exp Metastasis 25: 685-693, 2008

38. Jordan MA, Kamath K, Manna T, Okouneva T, Miller HP, Davis C, Littlefield BA and Wilson L: The primary antimitotic mechanism of action of the synthetic halichondrin E7389 is suppression of microtubule growth. Mol Cancer Ther 4: 1086-1095, 2005.

39. Dong C,LiZ, AlvarezR Jr,Feng XH and Goldschmidt-ClermontPJ: Microtubule binding to Smads may regulate TGF beta activity. Mol Cell 5: 27-34, 2000. 